\title{
CORRELATION BETWEEN THERMAL DIFFUSIVITY VARIATION AND QUALITY OF COLD PRESERVED FISH
}

\author{
F.A. Ansari * \\ Mechanical Engineering Department, A.M.U., Aligarh-202002, India \\ K.A. Abbas \\ Senior Research Officer, FET, MMU - Melaka Campus, 75450, Melaka, \\ Malaysia \\ M.M.H. Megat Ahmad \\ Head of Department, Mechanical \& Manufacturing Engineering, UPM, \\ Malaysia
}

Received 5 August 2002, Accepted 24 April 2003

\begin{abstract}
The present paper deals with establishment of correlation between thermal behaviour and quality of cold preserved fish. Experiments were designed and transient temperature-time variations were recorded at the center and other three equidistant locations during air blast cooling of slab shaped pieces of fresh water fish. A number of pieces from the same lot were cold preserved at $3^{\circ} \mathrm{C}$ for a period of 28 days and experiments were repeated daily.

Time-temperature records were used to determine thermal diffusivity of each sample using the empirical approach of the first author, reported elsewhere. It was observed that the measured thermal diffusivity increased up to 14 days and then stayed approximately constant up to the end of the preservation period ( 28 days). According to the reported literature, it was found that the shelf life of fish preserved at $3^{\circ} \mathrm{C}$ is 14 days. Regression analysis was made to develop an empirical correlation between thermal diffusivity and preservation time of the fish under investigation.
\end{abstract}

\section{NOMENCLATURE}

$\mathrm{Bi}=$ Biot number $\left(=\mathrm{h} \cdot \mathrm{x}_{0} / \mathrm{k}\right)$

$c_{p}=$ specific heat of fish $(\mathrm{J} / \mathrm{kg} \cdot \mathrm{K})$

$\mathrm{h}=$ surface film conductance $\left(\mathrm{W} / \mathrm{m}^{2} . \mathrm{K}\right)$

$\mathrm{k}=$ thermal conductivity $(\mathrm{W} / \mathrm{m} . \mathrm{K})$

Corresponding author e-mail: fa_ansari@yahoo.com 
$\mathrm{m}=$ shape index; 0 for infinite slab, 1 for infinite cylinder and 2 for sphere

$\mathrm{Nu}=$ Nusselt number $\left(=\mathrm{h} \cdot \mathrm{x}_{0} / \mathrm{k}_{\text {air }}\right)$

$\operatorname{Pr}=$ Prandtl number

$\mathrm{Re}=$ Reynolds number $\left(=\mathrm{v} \cdot \mathrm{x}_{0} / \gamma\right)$

$\mathrm{T}=$ temperature $\left({ }^{\circ} \mathrm{C}\right)$

$\mathrm{t}=$ time $(\mathrm{s})$

$\mathrm{U}=$ normalized temperature $\left[=\left(\mathrm{T}-\mathrm{T}_{\mathrm{cm}}\right) /\left(\mathrm{T}_{\mathrm{i}}-\mathrm{T}_{\mathrm{cm}}\right)\right]$

$\mathrm{W}=$ water content, $\%$ (on wet mass basis)

$\mathrm{X}=$ normalized space coordinate $\left(=\mathrm{x} / \mathrm{x}_{0}\right)$

$\mathrm{x}=$ distance from central plane, central axis or centre $(\mathrm{m})$

$\mathrm{x}_{0}=$ Half thickness or radius $(\mathrm{m})$

$\mathrm{Z}=$ number of days of cold preservation

\section{Greek letters}

$\alpha=$ thermal diffusivity of $\left(\mathrm{m}^{2} / \mathrm{s}\right)$

$\gamma=$ kinematics viscosity of air at mean temperature $\left(\mathrm{m}^{2} / \mathrm{s}\right)$

$\tau=$ Fourier number $\left(\alpha . t / x_{0}^{2}\right)$

\section{Subscripts and superscripts}

$\mathrm{cm}=$ cooling medium

$\mathrm{i}=$ initial

\section{INTRODUCTION}

Knowledge of food thermophysical properties and that of their variations is very important for making heat transfer analysis and for designing heat transfer equipment. Thermal diffusivity is the most important thermal property, as it includes the effects of properties like mass density, thermal conductivity and specific heat capacity.

During the course of cold preservation of fish, many chemical and biochemical changes occur in the fish tissues, which eventually lead to its spoilage. These changes influence the thermophysical properties of fish during the course of its deterioration. As soon as a fish dies, spoilage begins. Spoilage of fresh fish is a rather complex process and is caused by a number of inter-related reactions, some of which are suppressed by others. The factors that principally contribute to the spoilage are the degradation of protein with subsequent formation of various products like hypoxanthine, trimethylamine, development of oxidative rancidity and the action of microorganisms. So, the spoilage process will bring about changes in texture of the flesh and consequently will influence the thermal diffusivity, which is a comprehensive property. The enzyme action causes spoilage after death and thus brings out self-digestion, affecting the flavour, texture and appearance of the fish. The rate of self-digestion is much dependent on temperature. Chilling of the fish to just above the freezing point does not stop, but retards self- 
digestion. Heating can stop enzyme action and it is controlled to some extent by other methods, such as salting, frying, drying and marinating.

The objective of the present investigation is to study the variation of thermal diffusivity of fresh water fish of Malaysian origin during its preservation in unfrozen state. An attempt is made to use this important thermophysical property as an indicator of consumer acceptance. If correlation may be developed between the preservation time and thermal diffusivity, this would give a basis of digitally defining the quality of cold preserved fish, which is yet not known and which may eventually be a good tool for food technologists.

\section{MATERIAL AND METHODS}

Air-cooling of food packages involves only heat transfer from its surface. Mathematical modeling and analysis of such problems is easy. Both classical and numerical solutions of such problems have been reported by Ansari (1984, 1986), Ansari et al. (1987), Baird and Gaffney (1976), Dincer (1993), Hayakawa (1972), Pflug et al. (1965), and Pflug and Kopelman(1966). The surface film conductance values required to make these solutions are those calculated from the $\mathrm{Nu}$-Re correlations available in the literature. Chapman (1984) and Ansari (1984) have reported such correlations for many physical situations. Graphical solutions have also been reported by using the Gurnie-Lurie charts (1923) and Heisler charts (1947).

The generalized dimensionless transient heat conduction equation for isotropic solids during symmetric cooling with no internal heat generation can be written as:

$$
\frac{1}{X^{m}} \cdot \frac{\partial}{\partial X}\left(X^{m} \cdot \frac{\partial U}{\partial X}\right)=\frac{\partial U}{\partial \tau} \quad \text { for } \quad 0 \leq X \leq 1
$$

If the sample is initially at a uniform temperature and pure convection heat transfer takes place, the initial conditions and the surface and center boundary conditions will be defined respectively by the following equations:

$$
\begin{array}{llll}
U=1 & \text { at } & \tau=0 & 0 \leq \mathrm{X} \leq 1 \\
\frac{\partial U}{\partial X}=-B i \cdot U & \text { at } & \tau>0 & \mathrm{X}=1 \\
\frac{\partial U}{\partial X}=0 & \text { at } & \tau>0 & \mathrm{X}=0
\end{array}
$$

The above equations system is solved to predict temperature-time variation during cooling either by classical methods or by numerical techniques. Numerical methods, like finite-difference and finite element, are very extensively used these days. Out of the two numerical methods, finitedifference technique is more prevalent. For solving the equation system, the thermophysical properties and system parameters should be known before hand. It was reported by Ansari (1999) that explicit finite difference scheme yields quite satisfactory results. 
Surface film conductance needed to solve the equation system was calculated from the Nu-Re relations reported by Chapman (1984). For regular shaped bodies, Ansari (1984) wrote it in the following generalized form.

$N u \equiv p+q \cdot \operatorname{Re}^{r} \cdot \operatorname{Pr}^{s}$

The constants p, q, r and s in the eq. (5) are different for different shapes. For the three regular shapes, their values are given in Table 1 , given below.

Table 1 : Constants in EQ. ${ }^{(5)}$

\begin{tabular}{cccc}
\hline Constant & Infinite slab & Infinite cylinder & Sphere \\
\hline $\mathrm{p}$ & 0.0 & 0.0 & 0.1 \\
$\mathrm{q}$ & 0.664 & 0.26 & 0.3 \\
$\mathrm{r}$ & 0.5 & 0.6 & 0.5 \\
$\mathrm{~s}$ & 0.333 & -0.300 & 0.333 \\
\hline
\end{tabular}

The chilled air properties used to solve eq. (5), were read from property tables at the mean temperature. The thermal conductivity of food product was determined from the measured water content using the empirical correlation reported by Mascheroni (1989) and it is written below.

$k=0.1075+0.502 W+5.052 * 10^{-4} W . T$

With known properties and system parameters, eqs. (1)-(4) are solved to numerically generate temperature-time variation of any food product. Conversely, if experimental temperature-time record is known, the same scheme can be used to predict any unknown property or system parameter. Ansari (1984) used this method to determine thermal diffusivity as well as surface film conductance. During investigations, it was observed that the scheme was not always convergent. Sometimes, quite absurd results were obtained, which were discarded. This problem was not encountered while making temperature calculations. Later, to overcome this problem, an empirical equation was developed and reported by Ansari (1986) to replace the above system of equations with a single algebraic equation as given below.

$$
r=\left[a+b \cdot \operatorname{In}\left[\frac{\mathrm{i}}{X+0.2}\right]-\operatorname{In} U\right] /\left[c /\left(1+d / B i^{e}\right)\right]
$$

Making least square analysis of numerically generated data developed the above equation. Methodology used has been thoroughly explained by Ansari (1984). Equation (7) was found to be valid for $0 \leq X \leq 0.6$ and $(\tau>0.4$ and the regression constants $a, b, c, d$ and e for infinite slab, infinite cylinder and sphere are given in Table 2. 
Table 2 : Regression Constants in EQ. ${ }^{(7)}$

\begin{tabular}{cccc}
\hline Constant & infinite slab & infinite cylinder & sphere \\
\hline a & -0.042 & 0.121 & 0.296 \\
b & 0.167 & 0.201 & 0.228 \\
c & 2.467 & 5.783 & 9.870 \\
d & 2.24 & 2.45 & 2.700 \\
e & 1.02 & 1.040 & 1.070 \\
\hline
\end{tabular}

Equation (7) is capable of making a thorough heat transfer analysis during cooling of solid and liquid bodies. It makes the calculation procedure very simple and hand calculation may be adequate for it. Later, Ansari and his co-workers (1987) demonstrated that the equation yielded highly reliable results both for temperature calculations and property determination. The convergence problem associated with the numerical schemes for determining thermal properties and system parameters did not occur. With known temperature-time history, it was successfully used to determine the thermal diffusivity or surface film conductance. It was also demonstrated to be a superior method in that, it yielded effective values of thermal diffusivity and surface film conductance, which included the effect of moisture evaporation from the products exposed to chilled air stream. When these effective values were used to calculate temperature, the agreement with measured temperatures was superior to that by other heat and moisture schemes available in the literature like that of Narayan and Murthy (1977). During later experimental investigations on liquid food, Ansari (1995) had established that the empirical equation (7) is equally reliable in making heat transfer studies in liquid containers. The convective heat transfer coefficient calculated from experimental transient temperature records yielded a value much higher than that obtained from the eq. (5). It was reported to be due to the effect of thermally induced convection currents in the liquid. When temperature was calculated using this effective value, it was in better agreement with the measured temperature.

After the reliability of the empirical method was well established, it was used to determine the thermal diffusivity of fish and its variation with preservation time in unfrozen refrigerated state through temperature-time measurements when it was cooled in chilled air stream.

\section{EXPERIMENTAL SET UP AND PROCEDURE}

The experimental test rig has been designed and fabricated for air blast cooling of fish pieces. The schematic diagram of the test set-up has been shown in Fig. 1. It consisted of a $4 \mathrm{~m}$ long galvanized iron sheet air-duct of $0.33 \mathrm{~m}$ x $0.31 \mathrm{~m}$ section which was insulated with $15 \mathrm{~mm}$ thick glass wool. The air was cooled by passing it over the cooling coils of a R-22 refrigeration system with the help of centrifugal fan. The temperature of the circulating air inside the test duct was maintained constant at $1^{\circ} \mathrm{C}$ and controlled through the adjustable pre-heater, heater and defrosts heater. The dampers A, B, C and D were provided to control the circulation rate of air 


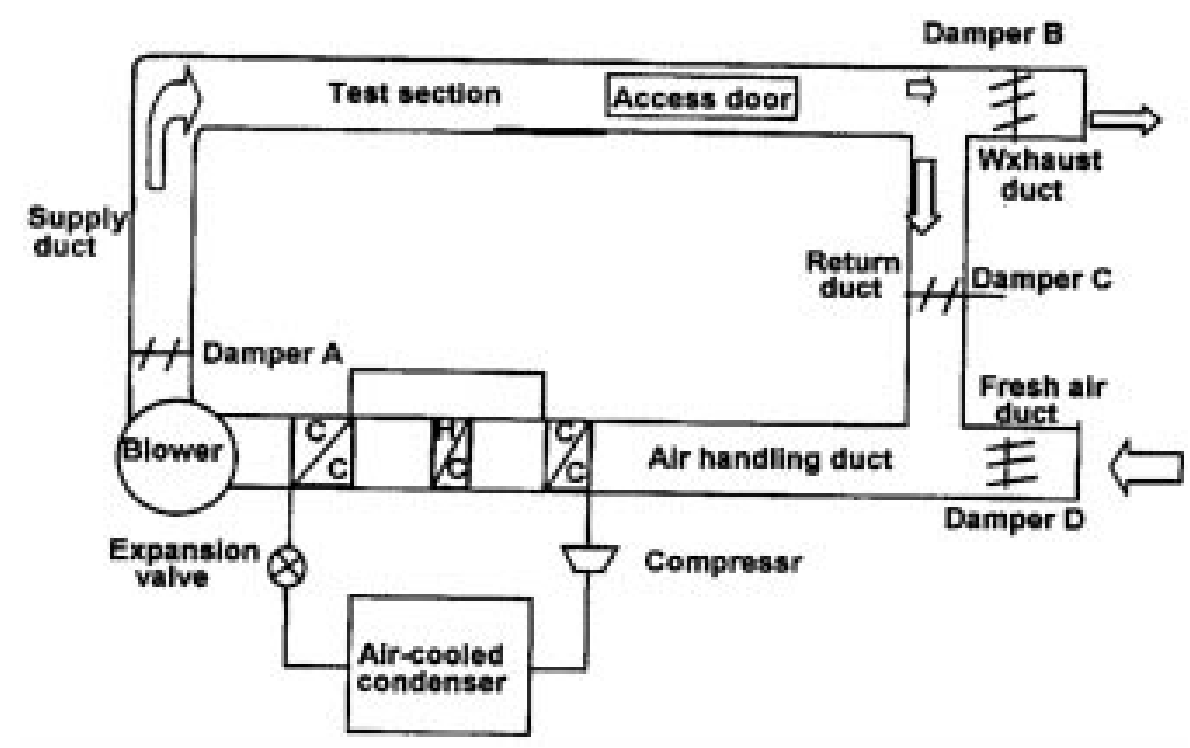

Figure 1 : Schematic diagram of air blast colling duct

passing over the test sample. The velocity of chilled air was kept constant throughout all the experiments at $5 \mathrm{~m} / \mathrm{s}$.

The test sample was prepared such that one dimensional heat transfer could take place. Fish pieces were cut with uniform thickness of $2.54 \mathrm{~cm}$. A fish piece was held between two $0.1 \mathrm{~mm}$ thick copper plates as shown in Fig. 2. The remaining four faces were thermally insulated so as one dimensional heat transfer could take place. For symmetrical cooling, the sample was suspended in the chilled air stream such that the conducting copper faces were parallel to the direction of the air stream. In order to fix the sample inside the test duct, two pairs of insulated hooks were attached to the inside of the upper and lower surfaces of the test duct. The test sample container was fastened to the upper and lower hooks with the help of thin cotton threads to avoid heat conduction. If $\mathrm{X}_{0}$ is the characteristic length (half thickness) of the fish sample, five copper-constantan thermocouples were put inside the flesh at the depths $\mathrm{X}_{0} / 5,2 \mathrm{X}_{0} / 5,3$ $\mathrm{X}_{0} / 5,4 \mathrm{X}_{0} / 5$ and $\mathrm{X}_{0}$ from the surface. In order to make it possible to insert the thermocouples at the desired depths, five fine holes were drilled at equal distances of $5 \mathrm{~mm}$. from each other on one of the copper sheets. The temperatures inside the fish flesh, and the dry bulb and wet bulb temperatures of the circulating air were measured with the help of 28 gauge copperconstantan thermocouples. The lead wires of all the thermocouples were connected with a data logger to obtain simultaneous temperature measurements at a specified equal time interval of one minute. Measurements on each sample were made for 60 minutes, when the temperature along the central plane approached the cooling air temperature within $0.5^{\circ} \mathrm{C}$.

A fresh lot was purchased from the market. It was ascertained that all the fish was in the same age group. Sufficient numbers of uniformly $2.54 \mathrm{~mm}$ thick pieces were cut so as they could be used for 30 days of experimentation. Three pieces of fresh fish were used for the first day and 

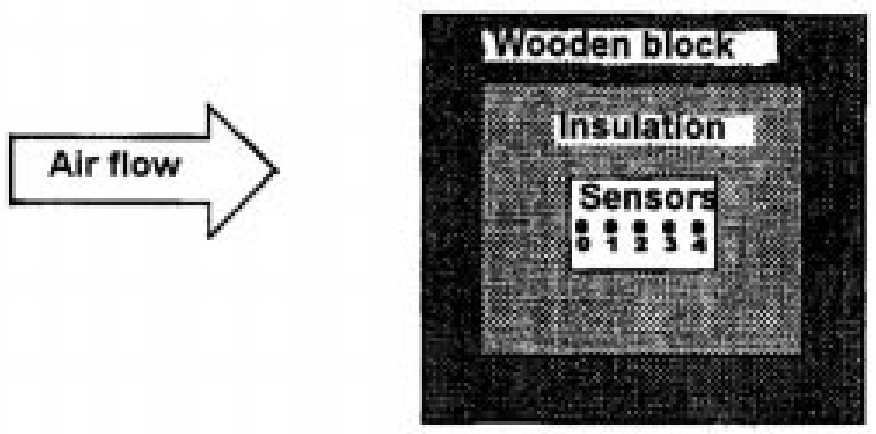

\section{Side view of the test package}
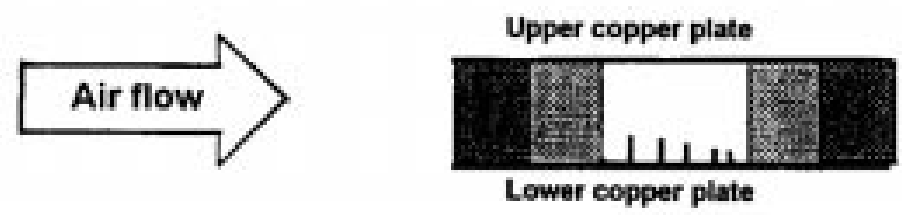

\section{Cross sectional view of the test package}

Figure 2 : Test container

the rest were preserved in a refrigerator at a uniform temperature of $3^{\circ} \mathrm{C}$. The air chilling plant was first run for nearly half an hour so as a steady temperature of $1^{\circ} \mathrm{C}$ was attained. The fish sample was first packed into test container, thermocouples were fixed at desired depths and the container was suspended properly inside the chilled air duct. As soon as fish sample was suspended the data logger was switched on and it was programmed to record temperatures at each one-minute time interval. On the first day, tests were carried out on three fresh samples. On subsequent days, three cold preserved fish samples were taken out from the refrigerator, first kept at the room temperature until their temperatures were stabilised to room temperature. Tests were then performed one by one on the three samples and data was collected for 28 days, until the fish was completely rotten.

\section{RESULTS AND DISCUSSION}

The transient temperature-time data was used to calculate thermal diffusivity by eq. (7). Average value was calculated for each day. As discussed earlier, eq. (7) gives accurate results during linear temperature variations. Figure 3 shows a typical temperature-time plot, in which initial temperature drop is fast and non-linear. This non-linear portion must be omitted while determining thermal diffusivity. As discussed earlier, similar inaccuracies occur when time temperature history near the surface is used. Due to these considerations, all the calculations were made for temperature records at $0 \leq \mathrm{X} \leq 0.6$ and $\tau>0.4$. 


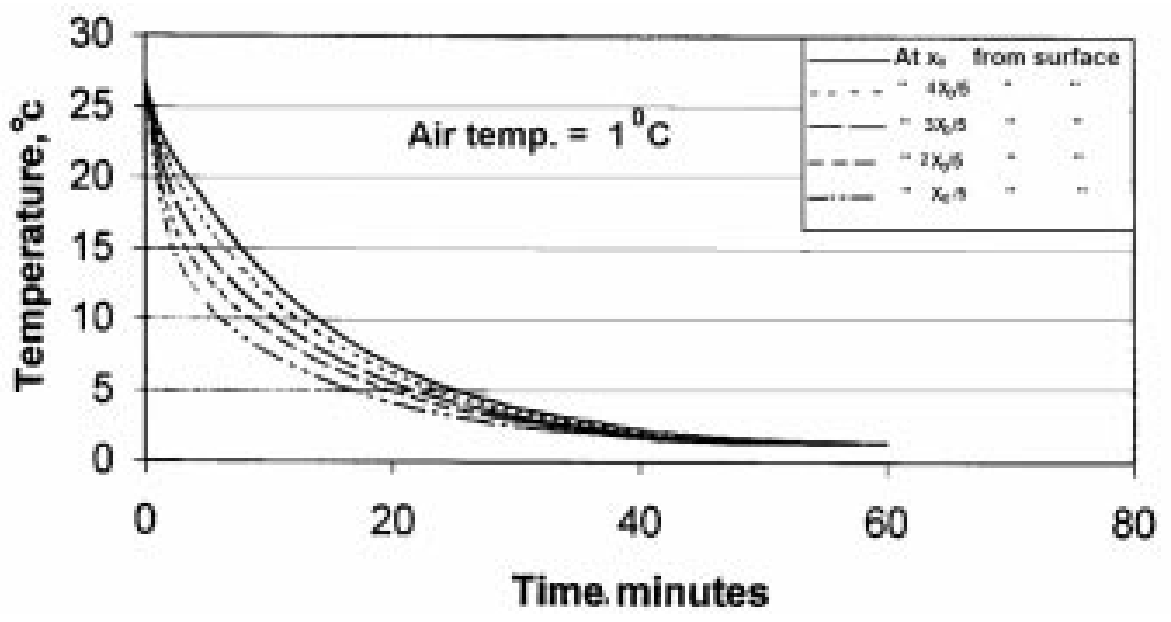

Figure 3 : Temperature-time plots

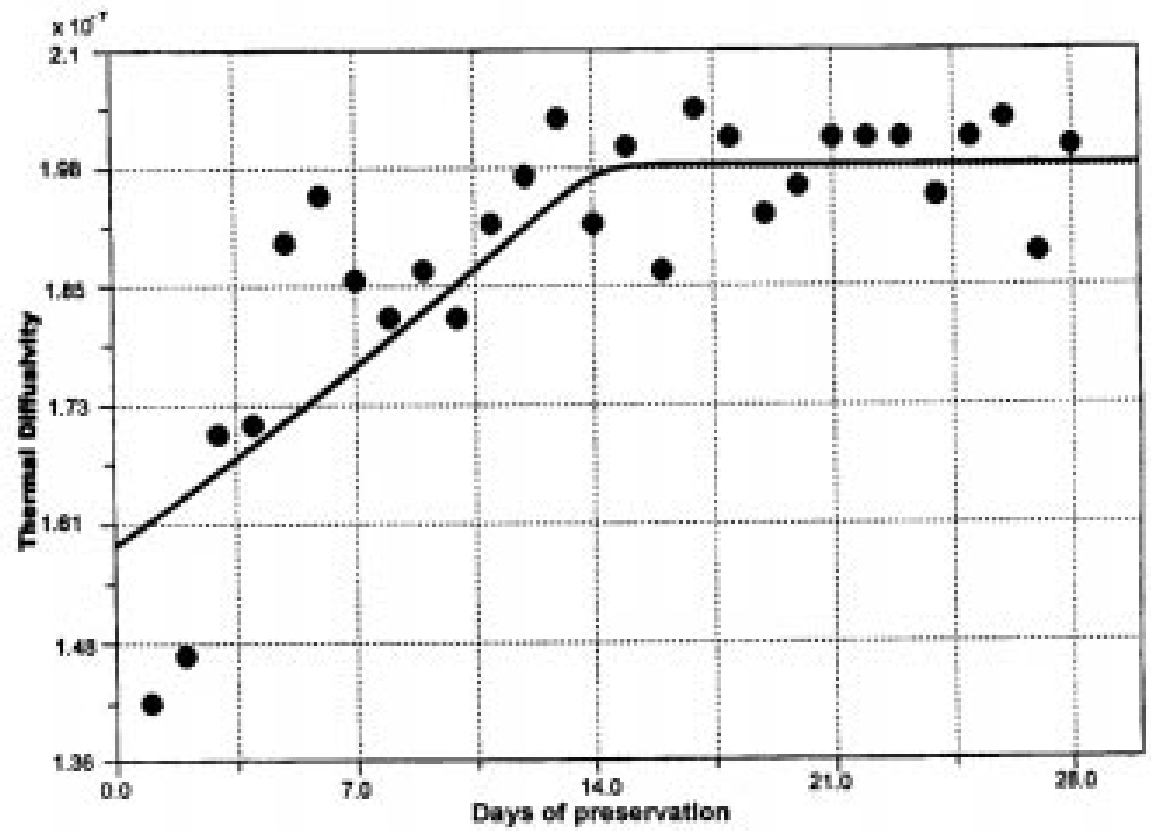

Figure 4 : Thermal diffusivity vs days of preservation plot

For two test sets, each extending for 28 days, three samples each day and four temperature time records on each sample, thermal diffusivity values were calculated. Average value was calculated for each day and averaging was done both for all the samples tested that day and all points. 
Average thermal diffusivity values were plotted against the days of preservation. The scatter of the values has been plotted in Fig. 4, which also shows the best-fit curve. It was observed that after 14 days of preservation time at a temperature of $3^{\circ} \mathrm{C}$, thermal diffusivity becomes constant. The literature review shows that at $3^{\circ} \mathrm{C}$ the acceptable life of fish is also 14 days. This shows a trend between the fish quality and one of its important sensory properties. When thermal diffusivity data was analyzed by least square method, the following correlation was obtained for the thermal diffusivity ratio $\left(\alpha / \alpha_{\text {fresh }}\right)$ as a function of days of preservation.

$$
\frac{\alpha}{\alpha}_{\text {fresh }}=1.392044(1+\exp (-1.38969-0.350267 . Z))^{-2.1}
$$

The above correlation may be used as an index of deterioration, freshness or consumer acceptance.

\section{CONCLUSION}

On the basis of a thorough heat transfer experiments and analyses performed in the present work, it can be concluded that:

1. During the course of preservation the fish material will be subjected to physical-chemical changes, which affect the value of the thermal diffusivity.

2. The Increasing behaviour of $\alpha$ during the preservation time can be recognised into two intervals, the first one shows high increase whereas this property thends to stabilize in the second interval.

3. A correlation has been developed for $\alpha / \alpha_{\text {fresh }}$ as a function of preservation time and temperature. On the basis of above function, the degree of freshness of the product may be numerically defined. The value of 1.0 for this quotient means absolutely fresh fish sample, and farther it is above 1.0, the lesser is the freshness of the product. At a maximum value, it becomes almost constant. When this stage is reached, the fish sample does not remain edible.

The first and second conclusions give essential information for heat transfer equipment designer. The last conclusion may be used as a mathematical tool by food technologist and fish retailers to define numerically the degree of freshness of a cold preserved fish batch.

\section{ACKNOWLEDGEMENT}

The present work has been funded through the internal research funding of the Multimedia University (MMU), Malaysia, which is thankfully acknowledged. The authors also acknowledge the experimental and computational facilities provided by the MMU. During the course of work, the teaching and technical staff of the Faculty of Food Sciences in the University Putra Malaysia has been kind enough to provide help and encouragement. All their encouragement and help is thankfully acknowledged. 


\section{REFERENCES}

1. Ansari, F.A. (1984), Heat and mass transfer analysis in cold preservation of food. Ph.D. Thesis. University of Roorkee, Roorkee, India.

2. Ansari, F.A. (1986), A.S.A.E. Trans., vol. 29, no. 5, pp. 1492-1497.

3. ASHRAE Guide, Data Book. Applications (1971), ASHRAE Inc., Atlanta, G.A.

4. ASHRAE Handbook of Fundamentals (1974), ASHRAE Inc., Atlanta, G.A.

5. Baird, C.D. and Gaffney, J.J. (1976), ASHRAE Trans., vol. 82, no. 2, pp. 525-540.

6. Chapman, A.J. (1984), Heat and Mass Transfer. 4th ed. Macmillan Publishing Co.

7. Dincer, I. (1993), Int. J. energy research, vol. 17, no. 1, pp. 9-18.

8. Gurnie, H.P. and Lurie, L. (1923), Industrial and Engineering Chemistry, vol. 15, p. 1170.

9. Hayakawa, K.I. (1972), ASHRAE J., vol. 14, no. 9, p. 65.

10. Heisler, M.P. (1947), ASME Trans, p. 277.

11. Mascheroni, R.H., Sanz, P.D. and Alonso, M.D. (1989), Latin American Applied Research vol. 19, pp. 155-163

12. Pflug, I.J., Blasdell, J.L. and Kopelman, I.J. (1965), ASHRAE Trans, vol. 71, no. 1, p. 238.

13. Pflug, I.J. and Kopelman, I.J. (1966), Bull. Int. J. Refrig. Annexe, p. 89.

14. Badri Narayana, K. and Krishna Murthy, M.V. (1977), Heat and mass transfer characteristics and the evaluation of thermal properties of moist spherical bodies, 4th National Conference on Heat and Mass Transfer, University of Roorkee, India, Nov. 21-23, 1997, p. 977.

15. Ansari, F.A. (1987), Int Communications in Heat and Mass Transfer, vol. 14, pp. 229235.

16. Ansari, F.A., Mughis, A. and Ahmad, M. (1987), Lebensm.-Wiss. U-Technol., Switzerland, vol. 20, no. 6, pp. 267-270.

17. Ansari, F.A. (1999), Energy Conversion and Mgmt, vol. 40, pp. 795-802. 